\title{
Recovery characteristics in patients undergoing short gynaecological day care procedures under sedation with dexmedetomidine vs propofol infusion
}

\author{
Indubala Maurya ${ }^{1}$, Hemanth Kumar Vadlamudi Reddy ${ }^{2}$, Jaya Velraj ${ }^{3 *}$ \\ Assistant Professor ${ }^{l}$, Super specialty Cancer Institute \& Hospital, C.G City, Lucknow India. \\ Professor ${ }^{2}$, Associate Professor ${ }^{3}$ Department of Anaesthesiology, Mahatma Gandhi Medical College \\ and Research Institute, Sri Balaji Vidyapeeth Deemed-to-be University, .Puducherry. India.
}

\begin{abstract}
Background and Aims: Postoperative psychomotor dysfunction is one of the deciding factors for discharge after daycare surgeries. Sedation for daycare procedures is commonly done using propofol and dexmedetomidine. Hence, we decided to study the recovery characteristics of dexmedetomidine and propofol in patients undergoing short gynaecological day care procedures.
\end{abstract}

\begin{abstract}
Methods:After getting informed consent, 40 patients aged between 18 to 65 years and ASA physical status 1 and 2 undergoing short gynaecological procedures were included for this double-blind prospective randomized controlled trial. All patients were educated about psychomotor tests preoperatively. Patients were randomized into two groups, Group P (propofol) and Group D (dexmedetomidine). Sedation was given using propofol or dexmedetomidine according to the group and titrated to achieve observer's assessment of alertness/sedation (OAA/S) scale 2-3. Recovery characteristics were assessed by modified Aldrete score, time to sit without support, finger tapping test and visual-spatial capacity memory test.
\end{abstract}

Results: Demographic variables, baseline finger tapping test and visual-spatial capacity memory test, duration and type of surgery were comparable. All forty patients tolerated the procedure with no signs of respiratory depression.Time to achieve modified Aldrete score 910 was significantly more in Group P compared to Group D ( $5.6 \pm 1.4 \mathrm{~min}$ vs $4.0 \pm 1.4 \mathrm{~min}$; $\mathrm{P}=0.002)$, while time to sit without support was significantly less in Group $\mathrm{P}(5.6 \pm 1.4 \mathrm{~min}$ vs $4.0 \pm 1.4 \mathrm{~min} ; \mathrm{P}=0.002$ ). Psychomotor tests during recovery and patient satisfaction score were comparable between the groups.

Conclusion:Dexmedetomidine and propofol have been found to have comparable recovery characteristics in daycare short gynaecological surgeries.

Keywords: Propofol; dexmedetomidine; recovery; daycare; sedatives

\section{Introduction}

Short-acting anaesthetic drugs help to administer anaesthesia for daycare procedures. This approach led to providing anaesthesia for various diagnostic and therapeutic procedures done as outpatient procedures which were done without anaesthesia. ${ }^{1}$

*Correspondence: Jaya Velraj

Email: jay2709@gmail.com

(iD

Received: 08/04/2019

Accepted:17/11/2019

DOI: http:/doi.org/10.4038/slja.v28i1.8480

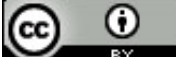

Post-procedural cognitive dysfunction, post procedural pain, nausea and vomiting were the causes for delayed discharge or re-admission and may cause anxiety to patients and increase financial burden. ${ }^{2,3}$ Out of these, post procedural cognitive recovery depends only on the pharmacodynamic property of sedative agent used and does not have drugs to treat at present. So, an ideal sedation agent for daycare surgeries should have a rapid onset of action, provide acceptable operative conditions, fewer side effects with smooth and early psychomotor recovery. Finger tapping test and visual-spatial memory test assess recovery of motor coordination, memory, attention and visual perception. $^{4-6}$ 
Propofol and dexmedetomidine have been used to provide sedation for various procedures because of their favourable pharmacokinetic properties. $^{7}$ There is a paucity of data comparing dexmedetomidine with propofol on recovery characteristics when used as a sedative for daycare surgeries. We designed this study to compare early psychomotor recovery after sedation under dexmedetomidine vs propofol in patients undergoing short gynaecological day care surgeries. We hypothesised that dexmedetomidine could be another alternative for sedation with comparable recovery characteristics.

\section{Methods}

This prospective randomized study was approved by the institutional human ethical committee and registered with the clinical trials registry. After getting informed consent, 40 patients aged between 18 to 65 years and ASA physical status 1 and 2 scheduled for elective daycare gynaecological surgery with a maximum of 30 minutes duration under intravenous sedation were recruited. Patients with known allergies, pregnancy, history of drug abuse or chronic pain, anticipated difficult airway, BMI $>35$, and who were not able to follow our instructions given for psychomotor tests were excluded.

Patients were randomized to Group P or Group $\mathrm{D}$ by block randomization using a computergenerated random number. Allocation concealment was done with the use of sequentially numbered, opaque sealed envelopes. The anaesthesia care provider who performed preoperative and postoperative psychomotor tests did not take part in intraoperative management.

All patients underwent thorough preoperative examination and were premedicated with oral alprazolam $0.25 \mathrm{mg}$, oral ranitidine $150 \mathrm{mg}$, and oral metoclopramide $10 \mathrm{mg}$ the night before and the morning of surgery. All patients were educated about psychomotor tests (finger tapping test, visual-spatial capacity memory test) and visual analogue scale. For the finger tapping test, the patients were asked to tap on the key of finger tapper device (WPS electronic tapping test, Western psychological services, Los Angeles, CA). The number of times the patient taps on the keyboard in 10 seconds was taken as the finger tap score. Five trials of 10 seconds each for each hand was done. The mean tapping score was calculated for each hand. For the visual-spatial memory test, patients were asked to observe a pattern of colored squares printed on the paper prepared manually and asked to remember. The paper was removed for a few seconds and then again shown with either all the items the same as before or with a single square has changed color. Observers are asked to say whether the display was exactly the same and response was recorded as YES/NO. Visual analogue scale, a horizontal line, $100 \mathrm{~mm}$ in length, anchored by word descriptors at each end. The patient was being asked to mark on the line the point that they feel represents perception of their pain.

In the operating room, $18 \mathrm{G}$ venous cannula was secured in the non-dominant upper limb and haemodynamics were monitored using standard monitoring (ECG, $\mathrm{SpO}_{2}$, and non-invasive arterial blood pressure). The patients were preloaded with $10 \mathrm{ml} / \mathrm{kg}$ of Ringer lactate solution. All patients received fentanyl $2 \mu \mathrm{g} / \mathrm{kg}$, and oxygen was administered through a nasal cannula at $2 \mathrm{~L} / \mathrm{min}$. After premedication, patients were allocated to either group (Group P or Group D) according to randomization. The sedation score was assessed using observer's assessment of alertness/sedation (OAA/S) scale (5-Responds readily to name spoken in normal tone, 4-Lethargic response to name spoken in normal tone, 3-Responds only after name is called loudly/or repeatedly, 2-Responds only after mild prodding shaking, 1-Does not respond to mild prodding or shaking). All patients in group $P$ received propofol infusion at $75-100 \mu \mathrm{g} / \mathrm{kg} / \mathrm{min}$, while group $\mathrm{D}$ received dexmedetomidine infusion at $1 \mu \mathrm{g} / \mathrm{kg}$ over 10 min followed by titrated dose $0.2-0.7 \mu \mathrm{g} / \mathrm{kg} / \mathrm{h}$, to achieve OAA/S scale 3-4. Once adequate sedationwas achieved, patients were positioned. Heart rate, blood pressure, respiratory rate, $\mathrm{SpO}_{2}$ and sedation scores were monitored every two minutes for 10 minutes, then every 5 minutes until the end of surgery.

Any intraoperative patient's movement was managed by accelerating infusion rates in both groups. In case, the patient showing a feature of excessive sedation (snoring, bradypnoea /apnoea) infusion rate was reduced. Any patients showing signs of respiratory depression was managed accordingly. Hypotension, defined as a decrease in systolic blood pressure by more than $20 \%$ from baseline or less than $90 \mathrm{~mm} \mathrm{Hg}$, was 
treated with i.v.mephentermine $3 \mathrm{mg}$ and boluses of intravenous fluid. Bradycardia, defined as heart rate (HR) less than $50 \mathrm{bpm}$, was treated with i.v. atropine $0.6 \mathrm{mg}$.

Once the procedure was over, infusions were stopped and this time noted as 0 . Modified Aldrete score was assessed every $1 \mathrm{~min}$ till the score reaches 9-10. Time to achieve modified Aldrete score 9 and time able to sit without support from time 0 were noted. VAS and psychomotor tests in propped up position every hour up to 4 hours after surgery were recorded by the same anaesthesia care provider who recorded pre-operative psychomotor tests. Any patient complaining of pain rescue analgesia was given as fentanyl $0.5 \mu \mathrm{g} / \mathrm{kg}$. All patients were monitored till 24 hours for any adverse effects like nausea and vomiting.Patient's satisfaction score $(4=$ excellent, $3=$ good, $2=$ fair and $1=$ poor) was assessed at $6 \mathrm{hrs}$ post-procedure.

\section{Statistics}

PS Power and Sample Size Calculation Software (Version 3.0, January 2009) was used to calculate the sample size using "average time for recovery" as the primary outcome variable. Based on the study done by Sethi et al. the average time for recovery was $16.3 \pm 5.5 \mathrm{~min}$ for propofol sedation. ${ }^{8}$ To find out the mean difference in time to recovery of 10 minutes with 10 minutes standard deviation between the groups with alfa error of 0.05 and power 0.80 , the calculated sample size was 17 patients in each group. SPSS 19.0 (SPSS inc, Chicago, Illinois) for windows was used for statistical analysis. Shapiro wilk test was done to test normality. Chi-square test or Fisher exact test was used for categorical variables and t-test or Mann-Whitney $U$ test for continuous variable. $\mathrm{P}<0.05$ was considered statistically significant.

\section{Results}

Out of 46 patients screened for recruitment, 40 patients, who fulfilled the inclusion and exclusion criteria were included for the study.

Both groups were comparablein relation to age distribution, body mass index, ASA Physical status, duration of anaesthesia and type of surgery (Table 1).

Baseline finger tapping test and visual-spatial memory test were within normal range and comparable between the groups. Baseline vitals (systolic blood pressure, diastolic blood pressure, heart rate, $\mathrm{SpO}_{2}$ ) were comparable.

Table 1: Demographic characteristics

\begin{tabular}{|c|c|c|c|}
\hline & $\begin{array}{ll}\begin{array}{l}\text { Group } \\
(\mathrm{N}=20)\end{array} & \mathrm{P} \\
\end{array}$ & $\begin{array}{l}\text { Group } \\
\mathrm{D}(\mathrm{N}=20)\end{array}$ & $\begin{array}{l}P \\
\text { value }\end{array}$ \\
\hline Age (years) & $47.40 \pm 12.41$ & $\begin{array}{l}47.55 \\
\pm 13.27\end{array}$ & 0.971 \\
\hline ASA-PS; $1 / 2$ & $13 / 7$ & $11 / 9$ & 0.519 \\
\hline BMI & $22.40 \pm 1 . .46$ & $21.7 \pm 1.41$ & 0.133 \\
\hline $\begin{array}{l}\text { Procedure; } \\
\text { DC/EB/FC }\end{array}$ & $4 / 6 / 10$ & $4 / 4 / 12$ & 0.748 \\
\hline $\begin{array}{ll}\begin{array}{l}\text { Duration } \\
\text { procedure }\end{array} & \text { of } \\
\end{array}$ & $32.25 \pm 3.79$ & $\begin{array}{l}31.75 \pm \\
3.72 \mathrm{~min}\end{array}$ & 0.677 \\
\hline \multicolumn{4}{|c|}{$\begin{array}{l}\text { ASA-PS: ASA physical status,BMI:Body Mass Index, } \\
\text { DC: Dilatation and curettage,EB: Endometrial biopsy,FC: } \\
\text { Fractional curettage }\end{array}$} \\
\hline
\end{tabular}

Recovery Characteristics (Primary outcome): All patients in either group tolerated the procedure with no signs of respiratory depression. Time to achieve modified Aldrete score 9-10 was significantly more in Group P as compared to Group D $(5.6 \pm 1.4 \mathrm{~min}$ vs $4.0 \pm 1.4 \mathrm{~min} ; \mathrm{P}=0.002$ ). While time to sit without support was significantly less in Group $\mathrm{P}$ as compared to Group D

$(12.0 \pm 2.3 \mathrm{~min}$ vs $13.5 \pm 2.2 \mathrm{~min} \mathrm{P}=0.031)$

Figure 2

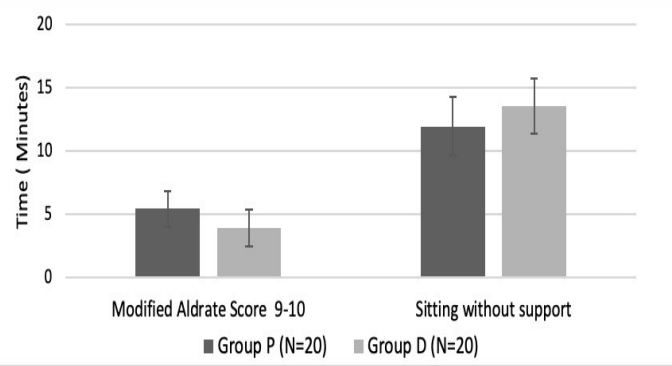

Finger tapping score in the dominant and nondominant hand was significantly reduced from the baseline at first hour in both groups and at $2^{\text {nd }}$ hour, both groups achieved the baseline score. 


\section{Figure 3}
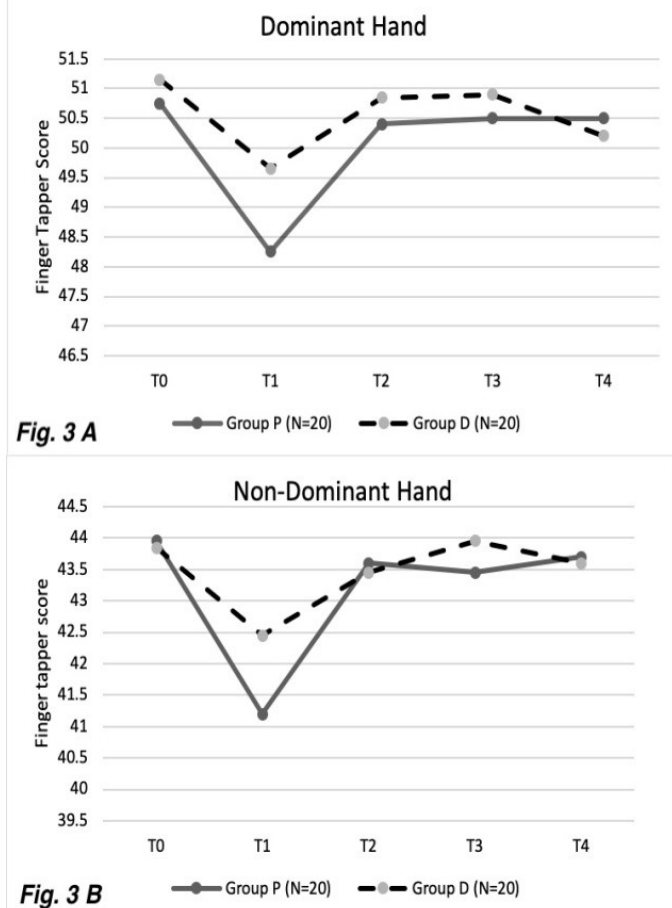

During visual-spatial memory test at the first hour, $85 \%$ of patients in group $\mathrm{P}$ and $90 \%$ in group D were able to tell correctly (17 vs 18 ; $\mathrm{P}$ $=0.291)$. At $2^{\text {nd }}$ hour onwards, all patients in both groups were able to tell correctly. All patients in either group were pain-free in the postoperative period. There was no incidence of nausea/vomiting. The median patient satisfaction score in group $\mathrm{D}$ was comparable to group $\mathrm{P}$ [3.5(3-4) vs 3(3-4); P: 0.352].

Haemodynamics (Secondary outcome):

Intraoperative systolic blood pressures were comparable between the groups at different time intervals except at 6 min (Figure 4a). Though group $\mathrm{D}$ had lower mean systolic blood pressure than group P $(107 \pm 10 \mathrm{mmHg}$ Vs $116 \pm 11 \mathrm{mmHg}$ $; \mathrm{P}=0.01)$ at $6 \mathrm{~min}$, there is no clinical significance. Diastolic blood pressures were comparable $(p>0.05)$ between the groups at different time intervals (Figure 4b). Two (10\%) patients showed a transient fall in SBP $<90 \mathrm{mmHg}$ in group $\mathrm{P}$, which was treated with a bolus of fluids. In group $\mathrm{D}$, none of the patients showed hypotension. Heart rate in group D was significantly lower than group P (Figure 4c). Six patients $(30 \%)$ in group $\mathrm{D}$ had heart rate less than 60 and none in group P.

\section{Figure 4}
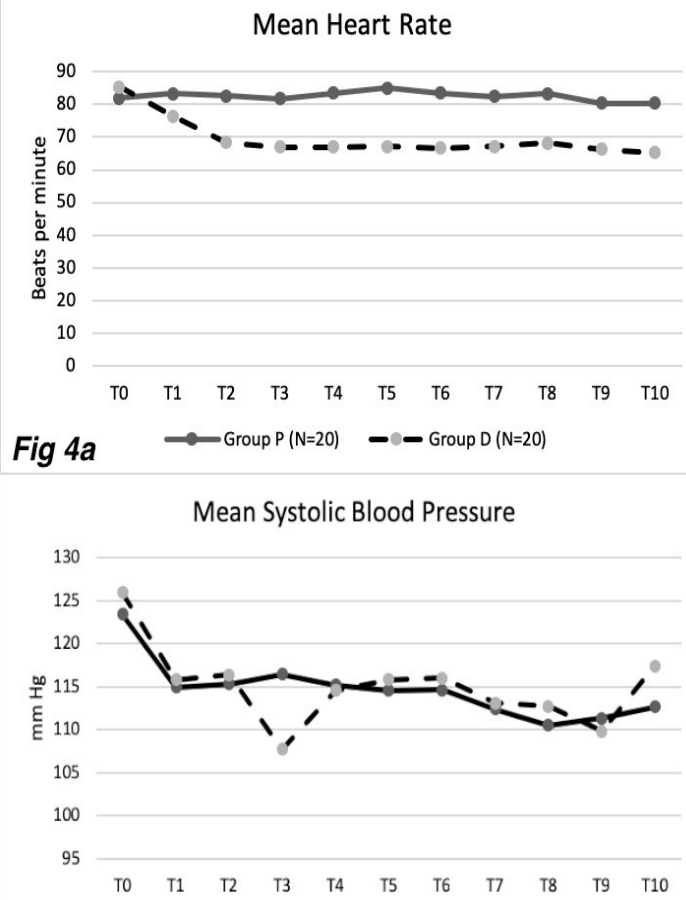

Fig $4 \boldsymbol{b} \quad \longrightarrow$ Group $\mathrm{P}(\mathrm{N}=20) \quad-\operatorname{Group~} \mathrm{N}(\mathrm{N}=20)$

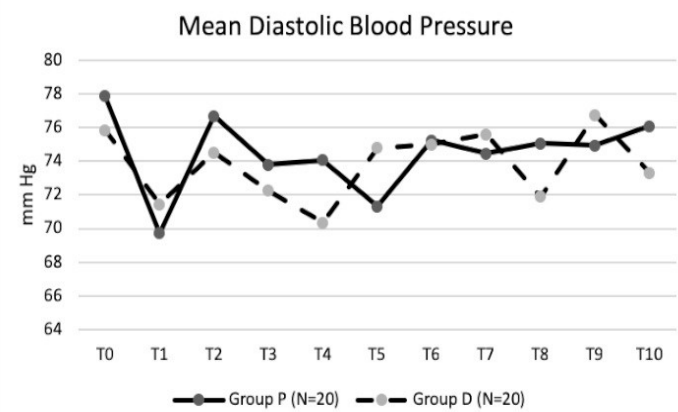

Fig $4 c$

\section{Discussion}

Postoperative recovery with respect to awakening (early recovery) and intermediate recovery (psychomotor recovery) is the foremost deciding factor for home readiness after daycare procedures under sedation. This study compared recovery characteristic after intravenous sedation under dexmedetomidine vs propofol in patients undergoing short gynaecological day care surgeries, and similar recovery characteristics were found in both groups.

Though early recovery characteristics were statistically significant, they were clinically insignificant (Time for MAS $\geq 9$ was $5.6 \mathrm{~min}$ vs $4.0 \mathrm{~min}$, time to sit with support was $12.0 \mathrm{vs}$ 
$13.5 \mathrm{~min})$. The intermediate recovery characteristics (Finger tapping score, visualspatial memory test) were statistically comparable. Sethi at al showed that sedation with dexmedetomidine had better recovery profile (Time for MAS $\geq 9$ : $4.4 \mathrm{~min}$ vs $16.2 \mathrm{~min}$, $\mathrm{P}<0.05$ ) in comparison to propofol in patients undergoing dilation and curettage in contrast to our finding. ${ }^{8}$ This may be because of open-label randomized control trial study design, so the possibility of bias toward intervention group can't be ruled out, and the fentanyl dose was lower $(1 \mu \mathrm{g} / \mathrm{kg})$. Previous studies have shown that propofol has early awakening and recovery compared to thiopentone, midazolam. ${ }^{6,9,10}$ In our study also, both groups achieved preoperative finger tapping score and visual-spatial memory by $2 \mathrm{hr}$. Young et al and Shukry et al, showed that intraoperative dexmedetomidine effectively reduced the incidence and intensity of emergence agitation without prolonging recovery and discharge time. ${ }^{11}$

Lower heart rate observed in group D may be due to selective $\alpha 2$ adrenoceptor agonist property of dexmedetomidine which inhibits central sympathetic outflow and causes vagomimetic action on the heart. Propofol is also known to produce bradycardia and fatal arrhythmia due to direct action on sinus activity and failure to induce reflex bradycardia. In our study, none of the patients had bradycardia, may be due to lower concentration used as infusion. ${ }^{12}$

Though none of the patients needed airway management in both the groups in our study, propofol is known to produce respiratory depression. ${ }^{13,14}$ This may be because of titrated infusion of propofol in lower concentration by anaesthesiologist instead of standard infusion rate. Dexmedetomidine has property devoid of respiratory depression which has the advantage over propofol. ${ }^{15,16}$

Limitations of the study:1. Selection of the psychomotor tests was one important aspect of this study. Only two psychomotor tests, i.e. Finger tappingtest and visual-spatial memory test,were studied because they were easy to understand and followed. Both psychomotor tests covered a few aspects of recovery such as motor coordination, memory, attention and visual perception. Addition of a few more psychomotor tests such as Trieger dot test, manual dexterity test etc. would give a better impression of intermediate recovery. 2 . The depth of sedation was measured by the observer's assessment of alertness/sedation (OAA/S) scale, which was subjective. Results would be more precise if assessed objectivelyusing entropy or bispectral index. 3 . We studied only patients undergoing minimally invasive procedures lasting less than an hour and in a small sample of the population.

\section{Conclusion}

Dexmedetomidine provided sedation with similar recovery characteristics and patient satisfaction score like propofol. So, dexmedetomidine could be an alternative to propofol for sedation along with fentanyl fordaycare short gynaecological surgeries.

\section{References}

1. Kulkarni S, Harsoor S, Chandrasekar M, et al. Consensus statement on anaesthesia for day care surgeries. Indian J Anaesth. 2017;61:110-24. https://doi.org/10.4103/ija.IJA 65916 PMid:28250479 PMCid:PMC5330067

2. Zulfiquer FA, Pattanayak K. Evaluation of unplanned admission following day surgery at a new surgical centre in London. Ambul Surg. 2009;4.

3. Awad IT, Chung F. Factors affecting recovery and discharge following ambulatory surgery. Can J Anaesth. 2006;53:858-72. https://doi.org/10.1007/BF03022828 PMid:16960263

4. Kurdi MS, Muthukalai SP. A comparison of the effect of two doses of oral melatonin with oral midazolam and placebo on pre-operative anxiety, cognition and psychomotor function in children: A randomised double-blind study. Indian $\mathrm{J}$ Anaesth. 2016;60:744-50.

https://doi.org/10.4103/0019-5049.191688 PMid:27761038 PMCid:PMC5064699

5. Austin D, Jimison H, Hayes T, Mattek N, Kaye J, Pavel M. Measuring motor speed through typing: a surrogate for the finger tapping test. Behav Res Methods. 2011;43:903-9. https://doi.org/10.3758/s13428-011-0100-1 PMid:21494919 PMCid:PMC3151309

6. Pawar S, Malde A. Time course of psychomotor, cognitive and ambulatory recovery after Propofol day case Anesthesia: A randomized double blind study. Internet J Anesthesiol 2009 Dec 31 [cited 2018 Nov 2];23(1). Available from:

ttp://ispub.com/IJA/23/1/4671

https://doi.org/10.5580/66c 
Velraj et al. Sri Lankan Journal of Anaesthesiology: 28(1):19-24(2020)

7. Naaz S, Ozair E. Dexmedetomidine in Current Anaesthesia Practice- A Review. J Clin Diagn Res JCDR. 2014;8(10):GE01-4. https://doi.org/10.7860/JCDR/2014/9624.4946 PMid:25478365 PMCid:PMC4253183

8. Sethi P, Sindhi S, Verma A, Tulsiani KL. Dexmedetomidine versus propofol in dilatation and curettage: An open-label pilot randomized controlled trial. Saudi J Anaesth. 2015;9:258. https://doi.org/10.4103/1658-354X.154699 PMid:26240542 PMCid:PMC4478816

9. Horiuchi A, Nakayama Y, Katsuyama Y, Ohmori S, Ichise Y, Tanaka N. Safety and driving ability following low-dose propofol sedation. Digestion. 2008;78:190-4.

https://doi.org/10.1159/000187118 PMid: 19092246

10. Hsu C-D, Huang J-M, Chuang Y-P, Wei H-Y, $\mathrm{Su}$ Y-C, Wu J-Y, et al. Propofol target-controlled infusion for sedated gastrointestinal endoscopy: A comparison of propofol alone versus propofolfentanyl-midazolam.

Kaohsiung J Med Sci. 2015;31:580-4. https://doi.org/10.1016/j.kjms.2015.09.004 PMid:26678938

11. Kwon S-Y, Joo J-D, Cheon G-Y, Oh H-S, In JH. Effects of Dexmedetomidine Infusion on the Recovery Profiles of Patients Undergoing Transurethral Resection. J Korean Med Sci. 2016;31:125.

https://doi.org/10.3346/jkms.2016.31.1.125

PMid:26770048 PMCid:PMC4712570

12. Tramèr, M. R., Moore, R. A. \&Mcquay, H. J. Propofol and bradycardia: causation, frequency and severity. British Journal of Anaesthesia 1997;78:642-651

https://doi.org/10.1093/bja/78.6.642

PMid:9215013

13. Kim, K.-M. et al. Pharmacokinetics and Pharmacodynamics of Propofol Microemulsion and Lipid Emulsion after an Intravenous Bolus and Variable Rate Infusion. Anesthes. 2007; 106:924-934.

https://doi.org/10.1097/01.anes.0000265151.789

$\underline{\text { 43.af }}$

PMid:17457123

14. Kaul, T. K., Gautam, P. L., Narula, N. \&Babra, J. K. Effect of Different Rates Of Infusion Of $1 \%$ \& 2\% Propofol For Induction Of Anaesthesia In Elderly Patients. Indian Journal of Anaesthesia. 2002;46:460.

15. Gertler, R., Brown, H. C., Mitchell, D. H. \& Silvius, E. N. Dexmedetomidine: a novel sedative-analgesic agent. Proc (BaylUniv Med Cent). 2001;14:13-21. https://doi.org/10.1080/08998280.2001.1192772 $\underline{5}$

PMid:16369581 PMCid:PMC1291306

16. Carollo, D. S., Nossaman, B. D. \&Ramadhyani, U. Dexmedetomidine: a review of clinical applications. Current Opinion in Anesthesiology. 2008;21:457.

https://doi.org/10.1097/ACO.0b013e328305e3ef PMid:18660652 